\title{
ATRIBUTOS FÍSICOS DO SOLO SOB DIFERENTES MANEJOS NO SUL DE RORAIMA.
}

\section{PHYSICAL ATTRIBUTES OF SOIL UNDER DIFFERENT MANAGEMENT IN THE SOUTH OF RORAIMA.}

\author{
Aline de Souza Lima ${ }^{1}$ \\ João José Costa Silva ${ }^{2}$ \\ Natália Machado Lacerda ${ }^{3}$ \\ Danieli Lazarini de Barros ${ }^{4}$ \\ Plínio Henrique Oliveira Gomide ${ }^{5}$
}

RESUMO: Os atributos do solo podem ser alterados em função do manejo empregado. Características como densidade do solo (Ds), resistência do solo à penetração (RP) e teor de água no solo (TAS) são importantes indicadores da qualidade física dos solos. $\mathrm{O}$ objetivo do trabalho foi demonstrar a influência de quatro tipos de sistemas de uso, nos atributos físicos do solo (Ds, RP e TAS) em uma propriedade rural em Roraima. Para determinação da Ds e TAS foram coletadas amostras indeformadas, e para avaliar a RP foi utilizado um penetrômetro de cone da marca penetroLOG. Os resultados indicaram diferença significativa entre os diferentes ambientes estudados. Revelando que a Ds e a RP obedeceram a uma sequência de acordo com o manejo empregado, sendo o ambiente pomar o que apresentou maiores valores destes atributos seguidos dos ambientes, pousio, pastagem e floresta nativa. Observou-se que o pisoteio de animais e tráfegos de máquinas aumentaram a Ds e a RP em relação à floresta nativa, evidenciando assim perda da qualidade. O levantamento dos atributos do solo, fornece informações importantes para um melhor conhecimento das condições impostas ao mesmo, quando se trata das alterações de floresta nativa para ambientes manejados em Roraima.

Palavras-chave: Compactação, Qualidade ambiental, Agropecuária.

ABSTRACT: The attributes of the soil can be changed according to the management used. Characteristics such as soil density $(D s)$, soil penetration resistance $(P R)$ and soil water content (TAS) have been important indicators of soil physical quality, since they

\footnotetext{
${ }^{1}$ Engenheira Agrônoma - Fiscal de Defesa Agropecuária de Roraima (ADERR), Rorainópolis, Brasil

2 Professores do curso de Agronomia da Universidade Estadual de Roraima (UERR), Campus Rorainópolis, Brasil

${ }^{3}$ Acadêmica do curso de Eng. Florestal da Universidade Estadual de Roraima (UERR), Campus Rorainópolis, Brasil

${ }^{4}$ Professora do Instituto Federal de Roraima (IFRR), Campus Boa Vista, Brasil

5 E-mail: plíniogomide@gmail.com
} 
are sensitive to the use and management that directly influence the development of the plants. The objective of this work was to demonstrate the influence of four types of systems of use on soil physical attributes (Ds, RP and TAS) in a rural property in the municipal it of Rorainópolis - RR. For the determination of DS and TAS, undisturbed soil samples were collected and a penetrometer was used to evaluate PR. The results indicated a significant difference between the different environments studied. Revealing that D sand PR followed a sequence according to the management of the soil used, and the orchard environment presented the highest values of these attributes followed by habitat, fallow, pasture and native forest. It was observed that trampling of animals and machine traffic increased $D$ sand $P R$ in relation to the native forest, thus evidencing loss of soil quality. Considering the region of the Amazonian floristic domain, one of the ecosystems with the greatest biodiversity of the planet, the soil attributes survey provides important information for a better knowledge of the conditions imposed on the soil sand the change of native forest to environments managed in Roraima.

Keywords: Compaction, Environmental quality, Farming

\section{INTRODUÇÃO}

O estado de Roraima têm se tornado importante fronteira agrícola, como expansão crescente das áreas cultivadas principalmente com soja nas regiões de lavrado ao norte do estado, o que tem atraído diversos investidores de todo o país. No município de Rorainópolis, localizado no Sul do estado, o setor primário representado pelas atividades agropecuária e madeireira representam o principal componente da economia local.

$\mathrm{O}$ avanço da fronteira agrícola provoca o desmatamento de áreas nativas, implicando em impactos ambientais muitas vezes ainda não mensurados para a região. Segundo Tormena et al. (2004) os sistemas de preparo do solo podem promover a degradação quanto qualidade física, com reflexos ambientais e na produtividade das culturas, dependendo do tipo de solo, do clima e da espécie cultivada. Desta forma é necessário que haja um conhecimento adequado das propriedades, funções e potencialidades do solo (KAMPF; CURI, 2012),

O uso intensivo de terras agricultáveis para a produção vegetal e animal tem causado degradação irreversível dos solos, sendo um problema mundial (STONE; SILVEIRA; MOREIRA, 2006). De acordo Lanzanova et al., (2010) a degradação física é uma das principais causas da baixa produtividade dos solos agrícolas. 
As características físicas do solo estão associadas, a infiltração, retenção e disponibilidade de água as plantas, córregos e águas de subsuperficies, resposta ao manejo e resistência à degradação, trocas de calor e gases com a atmosfera e raízes das plantas; e que possibilita o crescimento das raízes (REICHERT; REINERT; BRAIDA, 2003).

Para Mota; Freire; Junior (2013) um atributo indicador da qualidade do solo deve ser sensível às variações do manejo ao qual o solo está submetido, atributos como densidade do solo e resistência do solo à penetração são bastante utilizados como indicadores da qualidade física do solo. Segundo Araújo (2008) esses dois atributos estão entre os indicadores físicos mais utilizados e recomendados por pesquisadores para aferir os impactos causados nas funções do solo. Índices quantitativos de qualidade do solo podem servir como indicador de sua capacidade para a produção sustentável de plantas e de animais (ARATANI et al. 2009).

Atributos como densidade do solo e resistência à penetração podem fornecer informações importantes sobre a qualidade do solo, já que esses são sensíveis ao manejo, os quais influenciam diretamente no desenvolvimento da planta, e consequentemente na sua produção (SOUZA, 2010).

A densidade do solo é um importante atributo físico dos solos, pois fornece indicações a respeito do estado de sua conservação, sobretudo em sua influência em propriedades como infiltração e retenção de água no solo, desenvolvimento de raízes, trocas gasosas e suscetibilidade desse solo aos processos erosivos, sendo largamente utilizada na avaliação da compactação e/ou adensamento dos solos (GUARIZ et al. 2009).

A resistência do solo à penetração é uma propriedade que integra a avaliação da compactação do solo, o conteúdo de água, a textura e os tipos de minerais da argila presentes (MARCOLIN, 2006). Silveira et al., (2010) considera a resistência do solo à penetração a propriedade mais adequada para expressar o grau de compactação do solo e, consequentemente a facilidade de penetração das raízes.

Por ser um atributo fortemente influenciado pelo teor de água no solo, é necessário determinar o conteúdo de água no solo no momento da utilização do penetrômetro (ARAÚJO, 2008).

A Resistência do solo à penetração juntamente com a densidade do solo são atributos que apresentam relação direta com a velocidade de infiltração de água no solo, pois se um horizonte tem maior resistência à penetração e densidade do solo, haverá redução no volume 
de poros, reduzindo dessa forma a capacidade de retenção e infiltração de água no solo (CRUZ, 2012).

A disponibilidade de água no solo é um fator fundamental para o desenvolvimento e produtividade das culturas agrícolas (KAISER, 2010), influenciando importantes processos no solo e na planta tais como, movimento de água, compactação do solo, aeração do solo e desenvolvimento radicular (GUARIZ et al. 2009). O teor de água no solo tem forte influência sobre atributos físicos do solo como resistência do solo à penetração, já que esta varia de acordo com ciclos de umedecimento e secagem do solo (KAISER, 2010). Onde pequenas variações no teor de água determinam grandes variações nos valores de resistência do solo à penetração (SILVEIRA et al. 2010).

Em Roraima, estudos relativos à qualidade física dos solos nos agrossistemas são escassos, sendo praticamente inexistentes no município de Rorainópolis. Em virtude disso o objetivo deste trabalho foi demonstrar a influência de quatro tipos de sistemas de uso do solo nos atributos físicos em uma propriedade rural no município de Rorainópolis - RR.

\section{MATERIAL E MÉTODOS}

\section{LOCALIZAÇÃO DAS ÁREAS DE ESTUDO}

O estudo foi realizado em propriedade particular, situada às margens da rodovia BR 174, município de Rorainópolis. Localizada na região Sul de Roraima e situada nas coordenadas geográficas $60^{\circ} 25^{\prime} 47^{\prime \prime}$ de longitude Oeste e $00^{\circ} 56^{\prime} 46^{\prime \prime}$ de latitude Norte.

O clima da região, segundo classificação de (KÖPPEN, 1931) é Am (tropical chuvoso), com pequeno período de seca, com temperatura média anual de $27^{\circ} \mathrm{C}$ e precipitação média variando de 1.700 - $2000 \mathrm{~mm}$ (BARBOSA, 1997).

\section{HISTÓRICO E DESCRIÇÃO DAS ÁREAS DE ESTUDO.}

O ambiente de pastagem ocupa uma área de 6,0 hectares, localizada a $00^{\circ} 51^{\prime} 334^{\prime \prime} \mathrm{N}$ e $060^{\circ} 26^{\prime} 330^{\prime}$ 'W. Esta foi formada a mais de dez anos. A área foi convertida de floresta para pastagem através da derrubada e queima da vegetação. Atualmente é ocupada predominantemente com capim quicuio (Urochloa humidicola) e utilizado por bovinos de corte, não há ocorrência de queimadas nos últimos anos. Neste ambiente não foi realizada 
calagem nem adubação. O trânsito de máquinas se dá apenas quando são realizadas roçagens com trator. Pequenos trechos neste ambiente apresentam sinais de degradação do solo, com sulcos de erosão e solo descoberto.

O pomar ocupa uma área de 1,8 hectares, localizado a $00^{\circ} 51^{\prime} 229^{\prime}$ ' $\mathrm{N}$ e $060^{\circ} 26^{\prime} 511^{\prime}$ ' W. Área anteriormente utilizada com pastagem em avançado grau de degradação, com presença de vegetação secundária. Em 2006 foi realizada a limpeza da área através da derrubada e queima da vegetação secundária, que posteriormente foram enleiradas. Foram plantadas 1000 mudas de laranja no espaçamento de 3,0 x 6,0 metros. Em 2009 foi realizado plantio de milho nas entre-linhas do pomar. A partir de 2012 foi iniciada a limpeza e adubação do pomar. Não houve revolvimento do solo para implantação da cultura.

$\mathrm{O}$ ambiente em pousio ocupa uma área de 6,5 hectares, localizado a $00^{\circ} 51^{\prime} 203$ ' $\mathrm{N}$ e $060^{\circ} 26^{\prime} 374$ ', W. Anteriormente ocupada com pastagem degradada. Foi realizada queima, seguida pela limpeza da área com coleta de restos de vegetação, e posterior preparo convencional do solo no ano de 2011. Foi frequente a utilização de máquinas para o preparo do solo, as primeiras culturas implantadas nessa área foram melancia, milho, feijão-caupi e milho em esquema de rotação de culturas. Não foi realizada calagem. As adubações foram realizadas a cada ciclo de plantio para cada cultura implantada. Depois da retirada da produção dessas culturas a área ficou em pousio a partir do início do ano de 2014.

A floresta nativa ocupa uma área de 50 hectares, localizada a $00^{\circ} 51^{\prime} 232$ ' $\mathrm{N}$ e $060^{\circ} 26^{\prime}$ 783"' W. Ambiente com espécies arbóreas e arbustivas, característica do bioma Amazônico, apresentando grande quantidade de Hymenolobium Petraeum Ducke (Angelim -Pedra); Bagassaguianensis Aubl. (Tatajuba); Carinianaestrellensis (Raddi) Kuntze (Jequitibábranco); Bertholletia excelsa (Castanha-do-Brasil); Manilkarahuberi (Ducke) Stand (Maçaranduba); Manilkarabidentata (Maparajuba); Astrocaryumaculeatum (Tucumã); Goupia glabra Aubl (Cupiuba).

\section{CARACTERIZAÇÃO QUÍMICA E GRANULOMÉTRICA DO SOLO NOS DIFERENTES SISTEMAS DE USO NO MUNICÍPIO DE RORAINÓPOLIS.}

Foram coletadas com auxílio de um trado holandês, amostras de solo deformadas, na profundidade de $0-0,20 \mathrm{~m}$, distanciadas $10 \mathrm{~m}$ uma da outra, de modo a representar todo o ambiente de estudo. Em cada ambiente, foram retiradas seis amostras simples, para formar 
uma amostra composta de cada local. Estas amostras foram enviadas ao laboratório de análise de solo da Universidade Federal de Lavras, onde foram obtidos os seguintes resultados de análises granulométrica (Tabela 1) e análise química do solo (Tabela 2).

Tabela 1: Análise granulométrica

Table 1: Granulometricanalysis

\begin{tabular}{|c|c|c|c|c|c|c|c|}
\hline \multirow[t]{6}{*}{ 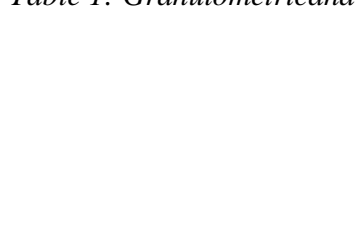 } & \multirow{2}{*}{ Ambiente } & \multicolumn{2}{|c|}{ Argila } & Silte & \multicolumn{2}{|r|}{ Areia } & MOS* \\
\hline & & \multicolumn{5}{|c|}{ 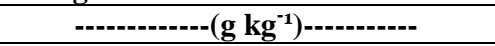 } & $\%$ \\
\hline & Pastagem & \multicolumn{2}{|c|}{269} & 92,5 & \multicolumn{2}{|c|}{638,4} & 2,34 \\
\hline & Pousio & \multicolumn{2}{|c|}{194,3} & 73,6 & \multicolumn{2}{|r|}{732,1} & 2,46 \\
\hline & Pomar & \multicolumn{2}{|c|}{257,1} & 108,2 & \multicolumn{2}{|r|}{634,7} & 2,46 \\
\hline & Floresta & \multicolumn{2}{|c|}{192,5} & 62,4 & \multicolumn{2}{|r|}{745,1} & 1,87 \\
\hline \multicolumn{8}{|c|}{ *MOS = Materia orgânica do solo } \\
\hline \multicolumn{8}{|l|}{$\begin{array}{l}\text { Tabela 2: Análise química } \\
\text { Table 2: Chemicalanalysis }\end{array}$} \\
\hline & \multirow{2}{*}{ Ambiente } & pH & $\mathrm{Ca}^{2+}$ & $\mathrm{Mg}^{2+}$ & $\mathbf{K}^{+}$ & $\mathbf{A l}^{3+}$ & $\mathbf{P}$ \\
\hline & & $\mathrm{H}_{2} \mathrm{O}$ & \multicolumn{4}{|c|}{-------- cmoldm $^{-3}$-. } & $\mathrm{mg} \mathrm{dm}^{-3}$ \\
\hline & Pastagem & 5,1 & 0,59 & 0,17 & 0,07 & 0,44 & 0,64 \\
\hline & Pousio & 4,6 & 0,2 & 0,1 & 0,15 & 0,74 & 9,51 \\
\hline & Pomar & 4,6 & 0,44 & 0,2 & 0,08 & 0,57 & 0,92 \\
\hline & Floresta & 4 & 0,04 & 0,06 & 0,04 & 0,99 & 0,92 \\
\hline
\end{tabular}

\section{AMOSTRAGEM}

As amostras de solo foram coletadas em de setembro de 2014, nos quatro ambientes da propriedade para caracterização física do solo. As amostras foram obtidas abrindo-se mini trincheiras com o auxílio de um enxadão a cada 30 metros na profundidade de 0-20 cmcom seis repetições em cada área amostral, totalizando vinte e quatro amostras. Foram coletadas amostras indeformadas para obtenção dos dados do teor de água no solo e densidade do solo, com seis repetições em cada área amostral. Esses torrões foram colocados em recipiente de alumínio numerados e identificados individualmente, e vedados com plástico filme para evitar perda de água.

A determinação da resistência do solo à penetração foi realizada através do uso de um penetrômetro de cone penetroLOG, modelo PLG1020 seguindo as normas da ASAE S313.1 (ASAE, 1983). As determinações foram realizadas até a profundidade de $40 \mathrm{~cm}$, sendo realizados cinco repetições de forma aleatória em cada ambiente de estudo.

\section{PROCESSAMENTO DA AMOSTRAGEM}


A determinação do teor de água no solo consiste na determinação do teor de água presente na amostra de solo, transportada em embalagem impermeável e vedada. As amostras foram acondicionadas em lata de alumínio numerada e de peso conhecido, foram pesadas e transferidas para estufa a $105-110^{\circ} \mathrm{C}$, ficando nesta condição durante 24 horas. Depois de retiradas da estufa e pesadas, foram efetuados os cálculos para obtenção dos valores de teor de água do solo pela seguinte equação: (EMBRAPA, 1997).

$$
U g=\frac{100(a-b)}{b} U g=\frac{100(a-b)}{b}
$$

(Equação 1)

Em que: Ug = Umidade gravimétrica em \%; a = peso da amostra úmida $(\mathrm{g})$; peso da amostra seca em g.

Para determinação da densidade do solo, o método utilizado foi o do torrão parafinado. Onde após seco em estufa, cada torrão foi pesado e mergulhado em parafina fundida até sua impermeabilização. Depois de impermeabilizado e esfriado o torrão parafinado foi introduzido em um béquer contendo água para obtenção do peso do torrão parafinado mergulhado em água. Após esse procedimento a densidade do solo foi determinada a partir dos seguintes cálculos: (EMBRAPA, 1997).

$$
\begin{array}{r}
D A=\frac{a}{b} D A=\frac{a}{b} \\
\quad(\text { Equação 2) }
\end{array}
$$

Em que: DA= Densidade aparente em g.cm ${ }^{-3} ; \mathrm{a}=$ peso do torrão seco a $105^{\circ} \mathrm{C} \mathrm{em} \mathrm{g} ; \mathrm{b}=$ volume do torrão $\mathrm{cm}^{3}$.

Para cálculo do volume do torrão foi utilizado a seguinte fórmula:

$$
\begin{gathered}
V T=[(a-b)-c] V T=[(a-b)-c] \\
(\text { Equação 3) }
\end{gathered}
$$

Em que: VT = Volume do torrão em $\mathrm{cm}^{3} ; \mathrm{a}=$ peso do torrão parafinado em $\mathrm{g} ; \mathrm{b}=$ peso do torrão parafinado mergulhado em água em $\mathrm{g} ; \mathrm{c}=$ volume da parafina $=$ peso da parafina $/ 0,90$.

\section{ANÁLISE ESTATÍSTICA DOS DADOS}

Os resultados foram tabulados em planilha Excel para análise dos dados pelo programa estatístico RStudio Team (2015), as médias foram comparadas pelo teste de Tukey a 5\% de probabilidade.

\section{RESULTADOS}

O teor de água do solo nos diferentes ambientes é apresentado na figura 1 abaixo: 


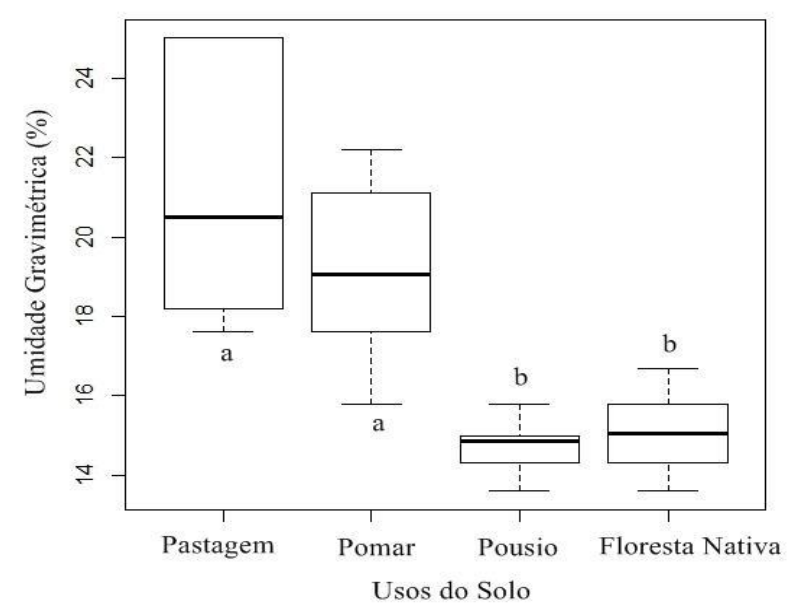

Figura 1: Teor de água no solo nos quatro ambientes avaliados em Rorainópolis - RR. Figure 1: Soilwatercontent in the four environmentsevaluated in Rorainópolis - RR

De acordo com os teores encontrados na figura 1, observa se que os ambientes pastagem e pomar apresentaram teores médios de água no solo superiores aos ambientes pousio e floresta nativa. Mesmo apresentando diferença estatística entre os ambientes avaliados, os teores de água nos diferentes ambientes foram baixos. Isso deve se a época em que foram realizadas as amostragens do solo, período de estiagem, no qual há redução da precipitação pluviométrica no estado (BARBOSA, 1997).

Na figura 2 estão apresentados os resultados de densidade do solo. O resultado da análise de variância $(\mathrm{R})$ indicou diferença significativa entre os diferentes sistemas de uso do solo, sendo a floresta nativa o ambiente que obteve o menor valor para este atributo seguido do ambiente pastagem.

Os valores mais baixos obtidos nestes ambientes devem-se ao aporte de material orgânico adicionado ao solo e também por não ter tido histórico de uso de maquinários agrícolas nestes ambientes, diferentemente do que foi encontrado para os ambientes pousio e pomar, os quais obtiveram valores maiores para este atributo em detrimento do intenso tráfego de máquinas nestes ambientes. 


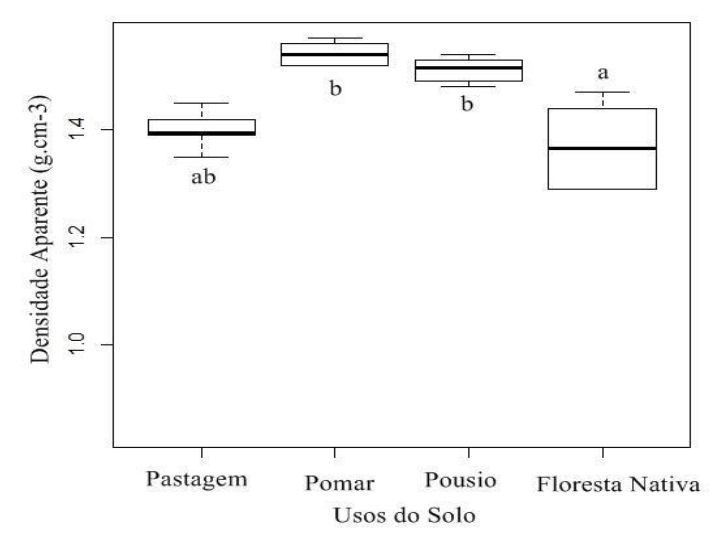

Figure 2: Densidade aparente do solo nos quatro ambientes avaliados em Rorainópolis - RR.

Figure 2: Soil bulk density in the four environmentsevaluated in Rorainópolis - RR.

De acordo com a figura 3, a floresta nativa apresentou menores valores de resistência a penetração quanto aos demais tratamentos, mantendo valores abaixo de $2 \mathrm{MPa}$. Este resultado é reflexo do valor de densidade do solo encontrado neste ambiente. Quanto menor a densidade do solo, mais leve será o mesmo, favorecendo deste modo à penetração das raízes no perfil do solo, o que aumenta a capacidade das mesmas em absorver água e nutrientes da solução do solo favorecendo o desenvolvimento das plantas.

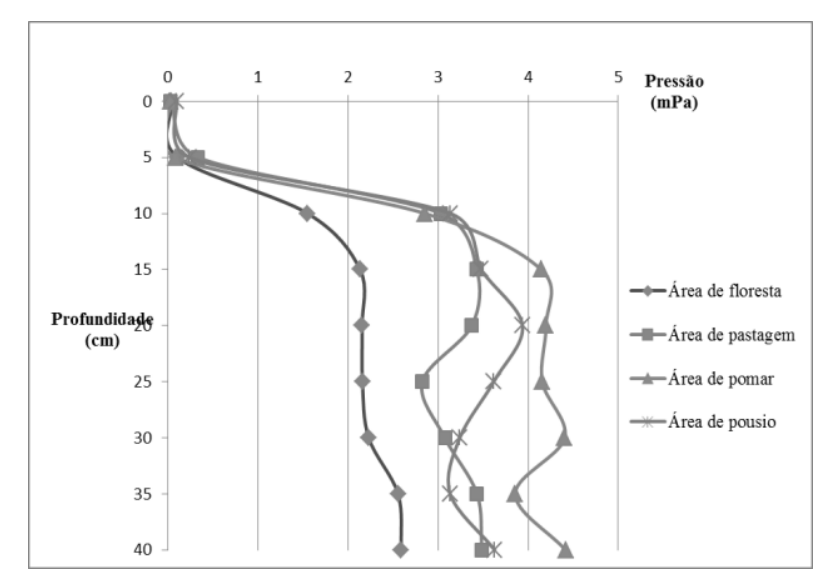

Figura 3: Resistência do solo à penetração $(\mathrm{MPa})$ em função da profundidade $(\mathrm{cm})$ nos quatro ambientes avaliados em Rorainópolis - RR.

Figure 3: Soil resistance to penetration (MPa) as a function of depth $(\mathrm{cm})$ in the four environments evaluated in Rorainópolis $-R R$.

\section{DISCUSSÃO}

\section{DENSIDADE DO SOLO}


O ambiente de floresta nativa apresentou densidade do solo significativamente menor entre os tratamentos. O que pode ser atribuído à ausência de ações antrópicas, maior proteção do solo contra intempéries e pela presença de matéria orgânica existentes nestes ambientes, já que esta atua como agente cimentante, contribuindo para uma melhor agregação do solo e consequentemente melhorando sua estrutura (MOREIRA; SIQUEIRA, 2006).

Segundo Bertolet al. (2000), o material orgânico adicionado ao solo pela vegetação, especialmente pelas raízes e pelas folhas e galhos na floresta nativa é que contribui para menores valores de densidade do solo nesse ambiente.

Muitos trabalhos têm evidenciado menores valores de densidade do solo em floresta nativa quando comparados a outros sistemas de uso do solo. Portugal; Costa; Costa (2010); Araújo; Tormena; Silva, (2004); Assis; Lanças (2005); Arataniet al. (2009).

Ao estudar a qualidade físico-hídrica do solo em agroecossistema e floresta nativa em Roraima, Souza, (2010) verificou menores valores de densidade do solo em ambiente de floresta com valores que variaram de $1,26 \mathrm{~g} . \mathrm{cm}^{-3}$ a $1,75 \mathrm{~g} . \mathrm{cm}^{-3}$, atribuindo tais valores a textura arenosa do solo. Cruz et al., (2014) avaliando os atributos físico-hídricos de um Argissolo amarelo sob floresta e savana naturais convertidas para pastagem em Roraima verificaram menores valores densidade do solo em floresta nativa em relação a floresta convertida em pastagem. Associando esses resultados à perda significativa de matéria orgânica nas camadas mais profundas do solo à que promoção de desestabilização da estrutura pela pressão causada pelo tráfego de máquinas e pisoteio animal. Entre os sistemas de uso do solo a densidade do solo diferiu estatisticamente e apresentou maiores valores nas áreas de pousio e pomar em relação às áreas com pastagem e floresta.

A menor densidade no ambiente de pastagem em relação ao ambiente de pomar e pousio pode se justificar há não compactação adicional do solo pelo tráfego de máquinas bem como ao incremento de material orgânico proveniente da decomposição radicular.

A maior densidade do solo nos ambientes de pomar e pousio podem ser atribuídas ao tráfego de máquinas nessas áreas, que no caso do pomar são utilizadas em operações como pulverização, roçagem e transporte da produção e no ambiente de pousio eram utilizados para preparo da área, semeadura, adubação e até para colheita da produção.

Trabalhando com vegetação secundária, citros e pastagem, Nunes; Farias; Lima (2013) encontraram maiores valores de densidade do solo em área de citros, atribuindo tais resultados 
ao uso de máquinas agrícola nesta área. Confirmado pelo trabalho de Strecket al. (2004) que trabalhou com tráfego induzido de máquinas encontrou alterações significativas de densidade do solo, com valores que variaram de $1,59 \mathrm{Mg} \cdot \mathrm{m}^{-3}$ para o tratamento sem compactação adicional e 1,85 Mg.m ${ }^{-3}$ para o tratamento com aplicação de pressão por tráfego.

Segundo Stone; Silveira; Moreira, (2006) a aplicação de cargas ao solo provoca sua compactação, resultando em modificações na estrutura e consequentemente no aumento de densidade (STONE; SILVEIRA; MOREIRA, 2006), pois com o tráfego de máquinas e implementos, principalmente em condições de altos teores de água no solo, ocorre alterações no arranjamento das partículas do solo, diminuindo geralmente o volume ocupado por determinada massa de solo e o tamanho dos poros que permitem livre circulação de ar e água (CAMARGO; ALLEONI, 2006).

A menor densidade do solo, no ambiente de pastagem em relação aos ambientes de pousio e pomar, podem ser justificados pela não compactação adicional provocada pelo trafego de máquinas neste ambiente.

Em todos os ambientes estudados a densidade do solo apresentou-se menor que 1,70 Mg. $\mathrm{m}^{-3}$, valor acima do qual é considerado restritivo ao crescimento radicular por (IMHOFF, et al. 2001).

\section{RESISTÊNCIA DO SOLO À PENETRAÇÃO}

A floresta primária apresentou menores valores de resistência a penetração quanto aos demais tratamentos, mantendo valores abaixo de 2 MPa na camada superficial do solo. Cruz et al. (2014) encontrou menores valores de resistência à penetração em floresta nativa quando comparada a conversão floresta/pastagem em Roraima, com valores de 0,39 Mpa para floresta nativa e 1,47 MPa para pastagem na camada de 0 a $10 \mathrm{~cm}$, na camada de $10-20 \mathrm{~cm}$ os valores foram de 1,90 MPa para floresta e 2,17 MPa para pastagem, em ambas as camadas os valores encontrados foram menores que os encontrados neste trabalho. Souza (2010) também verificou menores valores de resistência à penetração em floresta nativa em relação à agroecossistemas em Roraima. Esses resultados são atribuídos à ausência de ações antrópicas nestes ambientes. 
Até os 5,0 cm de profundidade a resistência à penetração apresentou-se abaixo de 0,5 MPa para todos os tratamentos, o que pode ser explicado pela presença matéria orgânica nessa camada. Pois a densidade dos materiais orgânicos é consideravelmente menor que as partículas minerais do solo, logo a mistura desses materiais resulta em uma menor densidade e consequentemente menor resistência à penetração (STONE; SILVEIRA; MOREIRA, 2006).

Os sistemas de uso do solo avaliados à exceção da floresta nativa, apresentaram já a partir dos 5,0 cm de profundidade valores de resistência a penetração acima de 2,0 $\mathrm{MPa}$, considerados restritivos ao crescimento radicular das plantas (IMHOFF et al. 2001). Esses elevados valores podem ser atribuídos ao uso agrícola do solo. Segundo Flores (2008) a pressão exercida sobre a superfície do solo seja por maquinário agrícola ou pisoteio animal afetam os atributos físicos do solo.

Para Silva (2003) valores críticos de resistência àpenetração são variáveis, estando associado ao tipo de planta, teor de água e tipo de manejo. Avaliando resistência a penetração no desenvolvimento radicular do milho Tavares filho et al. (2001), constatou que valor de resistência a penetração de 3,54 MPa não foi impeditivo ao crescimento radicular.

Por estar diretamente relacionada ao teor de água no solo, tem sido difícil estabelecer no campo a resistência do solo à penetração crítica, pois com o aumento do teor de água no solo a resistência do solo à penetração pode mudar rapidamente de uma possível condição limitante para outra não limitante (SILVA; REICHERT; REINERT, 2004).

Observou-se aumento de resistência à penetração nas camadas de 5,0 $-15,0 \mathrm{~cm}$ de profundidade para todos os ambientes, com destaque para o ambiente pomar. Cruz et al. (2014) encontrou maior resistência à penetração na camada de 10,0-20,0 cm de profundidade em relação a camada se $0-10,0 \mathrm{~cm}$ em conversão de floresta em Roraima. Isso indica a influência da matéria orgânica encontrada nas camadas superficiais do solo, para menores valores de densidade do solo. Barros et al. (2009) avaliando resistência à penetração em ambiente de savana no norte de Roraima encontrou valores de resistência a penetração de 4,7 Mpa na camada superficial e 9,3 Mpa em profundidade maiores que os encontrados neste trabalho.

Os maiores valores de resistência a penetração nos ambientes de pomar e pousio podem estar associados ao tráfego de máquinas nessas áreas. Strecket al. (2004) constatou que aumento de resistência a penetração ocorre com a aplicação de tráfego sobre o solo. $\mathrm{O}$ 
ambiente de pomar é o que concentra o maior tráfego de máquinas, o que pode justificar a maior resistência à penetração neste ambiente, uma vez que nesta área não houve revolvimento do solo para implantação da cultura. Silveira et al. (2010) encontrou valores médios de resistência a penetração de 6,22 MPa considerados altos em pomar de laranja.

$\mathrm{O}$ ambiente de pomar mesmo tendo apresentado maior teor de água no solo foi o que apresentou maior resistência à penetração, indicando dessa forma maior compactação do solo neste ambiente. Solos mais compactados atingem valores restritivos de resistência à penetração com menor variação no conteúdo de água (BLAINSKI et al. 2008).

Pode-se observar que os ambientes com maior resistência à penetração foram também os que apresentaram maior densidade do solo, seguindo a mesma ordem de resultados pomar>pousio>pastagem>floresta. Segundo (CRUZ et al. 2012) a resistência a penetração está diretamente relacionada com a densidade do solo, desta forma quando a densidade é elevada pode-se esperar também altos valores de resistência a penetração. Pois o aumento da densidade pode condicionar um novo arranjamento e acomodamento das partículas do solo favorecendo um incremento do número de contato entre elas, e aumentando dessa forma a resistência à penetração (SILVA et al. 2002).

Blainskiet al. (2008), constataram que valores de densidade superior a $1,75 \mathrm{Mg} \cdot \mathrm{m}^{-3} \mathrm{em}$ solo sob citros e 1,80 Mg.m ${ }^{-3}$ em solos sob culturas anuais, mesmo o solo estando em condições de elevada disponibilidade hídrica, a resistência a penetração é limitante ao crescimento radículas, alcançando valores maior que $2 \mathrm{MPa}$.

O menor teor de água encontrado no ambiente de pousio pode explicar os valores elevados de resistência a penetração. Segundo Kaiser (2010) em condições de baixo teor de água no solo ocorre um incremento da resistência à penetração. Uma vez que as partículas apresentam-se mais próximas, sendo difíceis de serem separadas por qualquer força externa (SILVEIRA et al. 2010). Este encontrou correlação significativa entre resistência do solo a penetração e teor de água em um solo com predominância da fração areia, atribuindo tais valores a alta permeabilidade e consequente variação no conteúdo de água nestes solos, já que pequenas variações no conteúdo de água determinam grandes variações nos valores de resistência a penetração.

A menor resistência à penetração encontrada no ambiente de pastagem em relação ao pousio e pomar pode ser justificada pelo maior teor de água encontrado neste ambiente. Essa 
redução de resistência à penetração com teor de água deve-se ao efeito lubrificante, que reduz a coesão entre as partículas na matriz do solo (TORMENA et al., 2007). O maior teor de água neste ambiente pode estar associado ao maior teor de argila verificado no mesmo. De acordo com Gomide et al. (2011) a diferença na composição textural do solo é um dos fatores determinantes do teor de umidade, solos de textura argilosa tendem a reter mais umidade do que os arenosos.

O ambiente de pastagem apesar de não ser o que apresentou maior resistência à penetração, também apresentou valores maiores que os considerados críticos. Silva Junior (2014) avaliando resistência à penetração em pastagem no município de Rorainópolis também encontrou valores elevados que variaram de 2,0 a 6,0 MPa. Fato este que pode ser explicado pelo pisoteio de animais. Segundo Imhoff; Silva; Tormena (2000) a compactação em pastagens ocorre devido à elevada pressão exercida sobre o solo pelas patas dos animais em função da elevada massa corporal aplicada em uma pequena área de contato.

Tomando como base o histórico das áreas pode-se observar que nos ambientes que sofreram pisoteio de animais ou tráfego de máquinas apresentaram aumento de resistência à penetração em relação á floresta nativa. Dessa forma podemos constatar que a conversão de floresta em sistemas de uso implica em perda de qualidade do solo, podendo assim comprometer a produtividade nestes solos.

\section{CONCLUSÕES}

Os atributos físicos analisados foram sensíveis ao refletirem o manejo e uso do solo nos diferentes ambientes avaliados, destacando-se a densidade do solo e resistência do solo a penetração, os quais apresentaram maiores valores no ambiente pomar, mostrando se uma área mais degradada, diferentemente do ambiente floresta nativa o qual apresentou menores valores desses atributos.

\section{AGRADECIMENTOS}

Ao Fábio Luiz Henz por ter cedido à área bem como auxiliado na coleta de solo.

\section{REFERÊNCIAS}


ARAÚJO, E.A. Qualidade do solo em ecossistema de mata nativa e pastagens na Região Leste do Acre, Amazônia Ocidental. 2008. 233f. Tese de Doutorado -Universidade Federal de Viçosa,Viçosa 2008.

ARATANI, R. G.FREDDI.O.da S. CENTURION. J. F. ANDRIOLI I.Qualidade física de um latossolo vermelho acriférrico sob diferentes sistemas de uso e manejo. Rev. Bras. Ciênc. Solo. Viçosa,v. 33, n. 3, jun. 2009 .

ASAE - American SocietyofAgriculturalEngineers.Soil Cone Penetrometer. In: AgriculturalEngineersYearbook; Standard S313-1. St. Joseph: ASAE, 1983. p.269-297.

ASSIS, R.L. de; LANCAS, K.P. Avaliação dos atributos físicos de um Nitossolo Vermelho distroférricosob sistema plantio direto, preparo convencional e mata nativa. Rev. Bras. Ciênc. Solo,Viçosa, v. 29, n. 4, jul. 2005.

BARBOSA, R.I. Distribuição de chuvas em Roraima. In: Barbosa R.I, Ferreira, E.F.G. e CastellonE.G. (Eds). Homem, Ambiente e Ecologia no Estado de Roraima. Instituto Nacional de Pesquisas da Amazonia e Governo do Estado de Roraima, Manaus, Amazonas, 1997c. p. 325-335.

BARROS, L.S.; VALE JÚNIOR, J.F.; SCHAEFER, C.E.G.R. \& MOURÃO, M. Perdas de solo e água em plantio de Acácia mangium Wild em Savana de Roraima, Norte da Amazônia. Rev. Bras. Ciênc. Solo. v.33, p. 235-475, 2009.

BERTOL, I.; ALMEIDA, J.A.; ALMEIDA, E.X. \& KURTZ, C. Propriedades físicas do solo relacionadas a diferentes níveis de oferta de forragem de capim-elefante-anão CV. Mott. Pesq. Agropec. Bras. v 35, p. 1047-1054, 2000.

BLAINSKI, E; TORMENA, C. A.; FIDALSKI, J.; GUIMARAES, R. M.L. Quantificaçãoda degradação física do solo por meio da curva de resistência do solo à penetração. Rev. Bras.Ciênc. Solo, v.32, p.975-983, 2008.

CAMARGO de, O. A.; ALLEONI, L.R.F. Conceitos Gerais de Compactação do solo.Disponível em: <http://www.infobibos.com/Artigos/CompSolo/Comp1.htm>. Acesso em: $11 / 10 / 2014$.

KAMPF, N.; CURI, N. Conceito de solo e sua evolução histórica. In: KER, J.C. (coordenador). Pedologia. Viçosa: SBCS, p.1-20,2012.

CRUZ, Diego Lima de Souza et al . Atributos físico-hídricos de um Argissolo amarelo sob Floresta e savana naturais convertidas para pastagem em Roraima. Rev. Bras. Ciênc. Solo,Viçosa, v. 38, n. 1, fev. 2014.

CRUZ, D. L. de S. Atributos físicos de argissolo amarelo sob floresta e savanas naturaise cultivados com pastagem em Roraima. 2012. 95 pag. Dissertação de mestrado. Universidade Federal de Roraima, Boa Vista, 2012. 
EMPRESA BRASILEIRA DE PESQUISA AGROPECUARIA-EMBRAPA. Centro Nacional de Pesquisa de Solos. Manual de métodos de analise de solo. 2ed. Rio de Janeiro,1997.212p.

GOMIDE, P. H. O.; SILVA, M. L. N.; SOARES, C. R. F. S. Atributos físicos, químicos e biológicos do solo em ambientes de voçorocas no município de Lavras - MG. Rev. Bras. Ciênc. Solo, Viçosa, v.35, p.567-577, 2011.

GUARIZ, H.R.; CAMPANHARO,W.A.; PICOLI,M. H. S.;CECÍLIO, R.A.;HOLLANDA, M.P. de. Variação daumidade e da densidade do solo sob diferentes coberturas vegetais. Rev. Bras. Agroecologia, v.4, n. 2, p. 3293-3296, 2009.

IMHOFF, S., SILVA, A. D., DIAS JUNIOR, M. D. S., \& TORMENA, C. A. Quantificação de pressões críticas para o crescimento das plantas.Rev. Bras. Ci. Solo, Viçosa, v.25, p.11$18,2001$.

KAISER, D.R. Estrutura e água em argissolosob distintos preparos na cultura do milho. 2010. 151f. 2010. Tese de Doutorado. Tese (Doutorado em Ciência do Solo) Universidade Federal de Santa Maria, Rio Grande do Sul, 2010.

KÖPPEN,W.1931.Climatologia. México, Fundo de Cultura Econômica.

LANZANOVA, M. E.,Eltz, F. L. F., NICOLOSO, R. D. S., AMADO, T. J. C., REINERT, D. J.,\& ROCHA, M. D. Atributos físicos de um Argissolo em sistemas de culturas de longa duração sob semeadura direta. Rev. Bras. Ciênc. Solo, v 34, n 4, p 1333-1342, 2010.

MARCOLIN. C. D. Propriedades físicas de nitossolo e Latossolos argilosos sob plantio direto. 2006. 110f . Dissertação de mestrado, Universidade de Passo Fundo, Passo Fundo 2006.

MOREIRA, F. M. S.; SIQUEIRA, J. O. Matéria Orgânica do Solo. Microbiologia e Bioquímica do Solo. 2 ed. UFLA, Lavras, 2006. 83-161 p.

MOTA, J.C.A; FREIRE, A.G; ASSIS Jr R.N.de. Qualidade física de um cambissolosob sistemas de manejo. Rev. Bras. Ciênc. Solo,Viçosa, v. 37, n. 5, 2013.

NUNES, D.S. de; FARIAS,P.R.S.da; DE LIMA, H.V. Atributos físicos e matéria orgânica em sistemas de uso do solo. EDUCAmazônia, v. 10, n. 1, p. 109-125, 2013.

PORTUGAL, A.F; COSTA, O.D.V; COSTA, L.M.da. Propriedades físicas e químicas do solo em áreas com sistemas produtivos e mata na região da Zona da Mata mineira. Rev. Bras. Ciênc. Solo, Viçosa , v. 34, n. 2, abr. 2010.

REICHERT J.M, REINERT D.J \& BRAIDA J.A. Qualidade dos solos e sustentabilidade de sistemas agrícolas. Ciência \& Ambiente, v 27, p 29-48, 2003. 
SEPLAN: Informações socioeconômicas do município de Rorainópolis-RR 2014 SEPLAN (Secretária Est. de Planejamento e Desenvolvimento). Disponível em: <http://www.seplan.rr.gov.br/roraimaemnumeros/dados_municipios/Rorainopolis.pdf> acessado em12 de setembro. 2014.

SILVA, V. R.; REINERT, D. J.; REICHERT, J. M. Fatores controladores da compressibilidade de um Argissolo Vermelho Amarelo distrófico arênico e de um Latossolo Vermelho distrófico típico. I - Estado inicial decompactação. Rev. Bras. Ciênc. Solo, v.26, p.1-8, 2002.

SILVA, V. R. Propriedades físicas e hídricas em solos sob diferentes estados de compactação. 2003. $171 \mathrm{f}$. Tese (Doutorado em Agronomia) - Universidade Federal de Santa Maria, Rio Grande do Sul, 2003.

SILVA, V.R.da; REICHERT, J.M; REINERT, D.J. Variabilidade espacial da resistência do solo à penetração em plantio direto. Cienc. Rural, Santa Maria,v. 34, n. 2, abr. 2004 .

SILVA Jr, N.Indicadores da degradação de pastagens em três propriedades rurais no município de Rorainópolis. 2014.. 89 p. trabalho de Conclusão de curso (graduação em Agronomia) Universidade Estadual de Roraima. Rorainópolis, 2014.

SILVEIRA, D.C.; MELO FILHO, J.F.; SACRAMENTO, J.A.A.S. \& SILVEIRA, E.C.P. Relação umidade versus resistência à penetração para um Argissolo Amarelo distrocoeso no Recôncavo da Bahia. Rev. Bras. Ciênc. Solo, ed. 34, p 659-667, 2010.

SOUZA, M.I.L. Qualidade físico-hídrica de um Argissolo Vermelho-Amarelo sob agroecossistema e floresta natural em Roraima.2010. 91f. Dissertação de Mestrado.UniversidadeFederalde Roraima, Boa Vista, 2010.

STONE, L.F; SILVEIRA, P.M; MOREIRA, J.A.A. Atributos físico-hídricos do solo sob plantio direto. Embrapa Arroz e Feijão, 2006.

STRECK, C.A.et al . Modificações em propriedades físicas com a compactação do solo causada pelo tráfego induzido de um trator em plantio direto. Ciênc. Rural, Santa Maria, v. 34, n. 3, jun. 2004 .

TAVARES F.J. et al. Resistência à penetração e desenvolvimento do sistema radicular do milho (Zeamays) sob diferentes sistemas de manejo em um Latossolo Roxo. Rev. Bras. Ciênc. Solo, Viçosa, n. 3, p. 725-730, 2001.

TORMENA, C. A., FIlHO, P. S. V., GONÇAlves, A. C., ARAÚJO, M. A., \& PINTRO, J. C. Influência de diferentes sistemas de preparo do solo nas propriedades físicas de um L físicas de um Latossolo Vermelho distrófico vermelho distrófico. Rev. Bras de Eng. Agrí. Amb., ed.8, n 1, p 65-71, 2004. 